
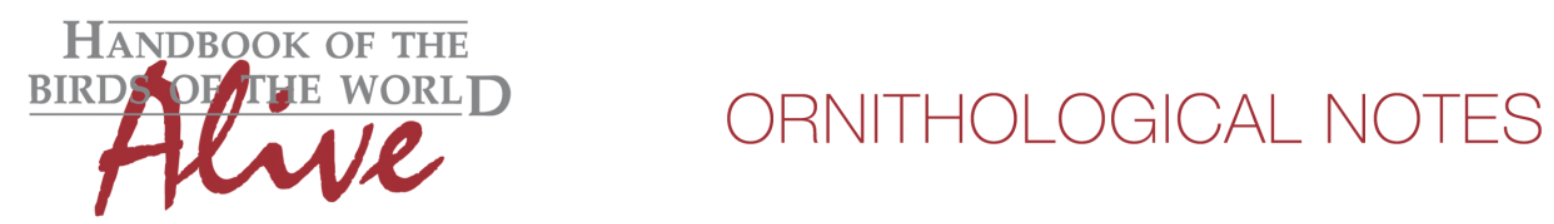

\title{
Notes on the vocalizations of Mottled Owl (Ciccaba virgata)
}

Peter Boesman

In the following text, I briefly analyze and compare the voice of the different races of Mottled Owl (Ciccaba virgata). I also try to quantify the extent of any vocal differences using the criteria proposed by Tobias et al. (2010), as a basis for taxonomic review. I have made use of sound recordings available online at Xeno Canto (XC) and the Macaulay Library (ML).

The available recordings suggest that there are two distinct vocal groups.

Group 1. Song is a series of typically 4-9 short emphatic sharply overslurred hoots. This voice can be heard in Middle America, Pacific South America (south to NW Peru) and NW South America, as illustrated in the following examples grouped by (presumed) subspecies:

\section{squamulata}

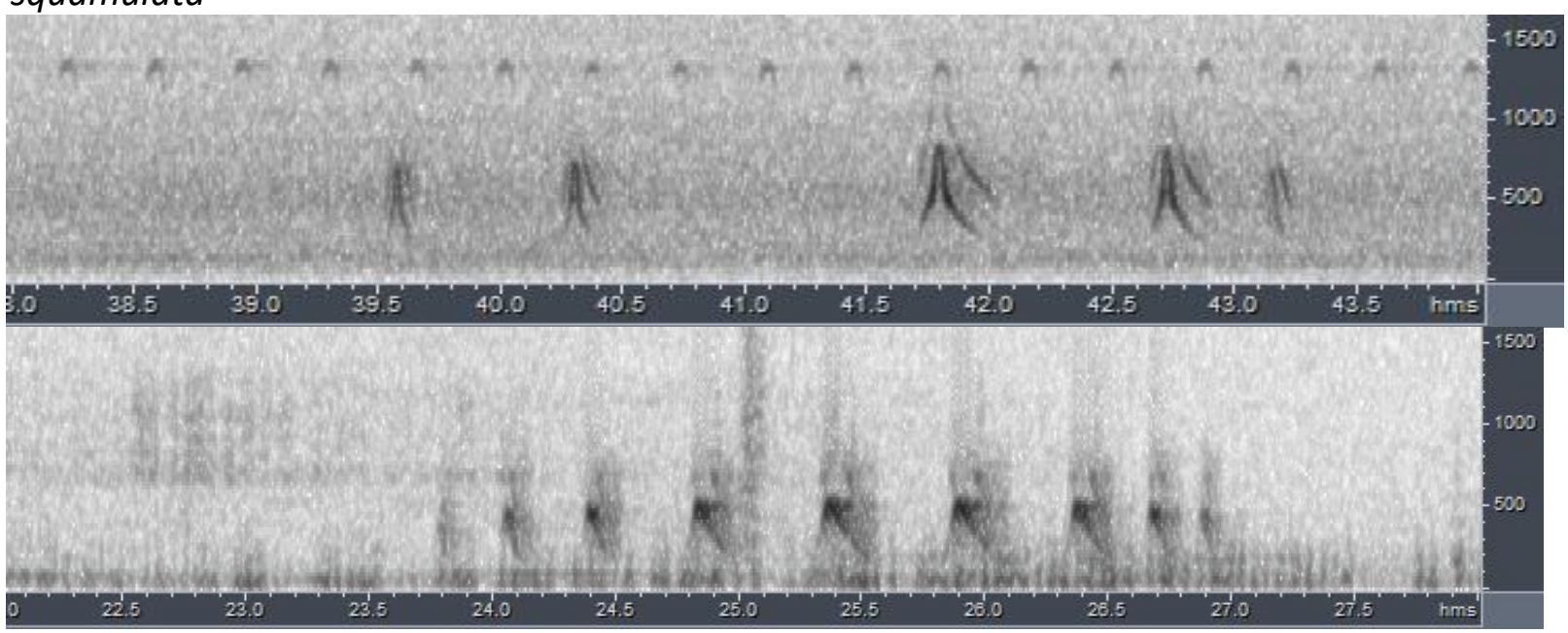

From top to bottom: XC2300099: Colima, Mexico, Peter Boesman; XC170476: Nayarit, Mexico, Erik Peñaloza.

\section{tamaulipensis}

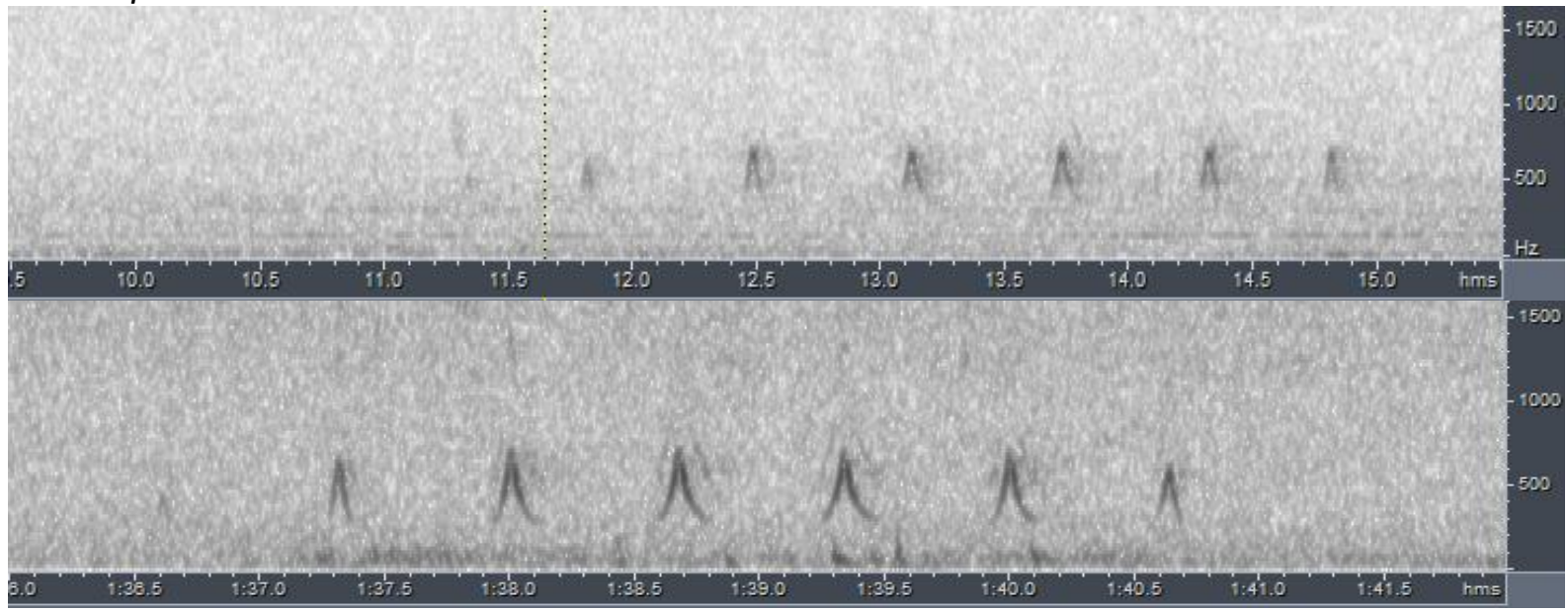

From top to bottom: XC58055: Tamaulipas, Mexico, Jon King; XC28882: Tamaulipas, Mexico, Dan Lane. 


\section{Hos Allve}

\section{ORNITHOLOGICAL NOTES}

centralis

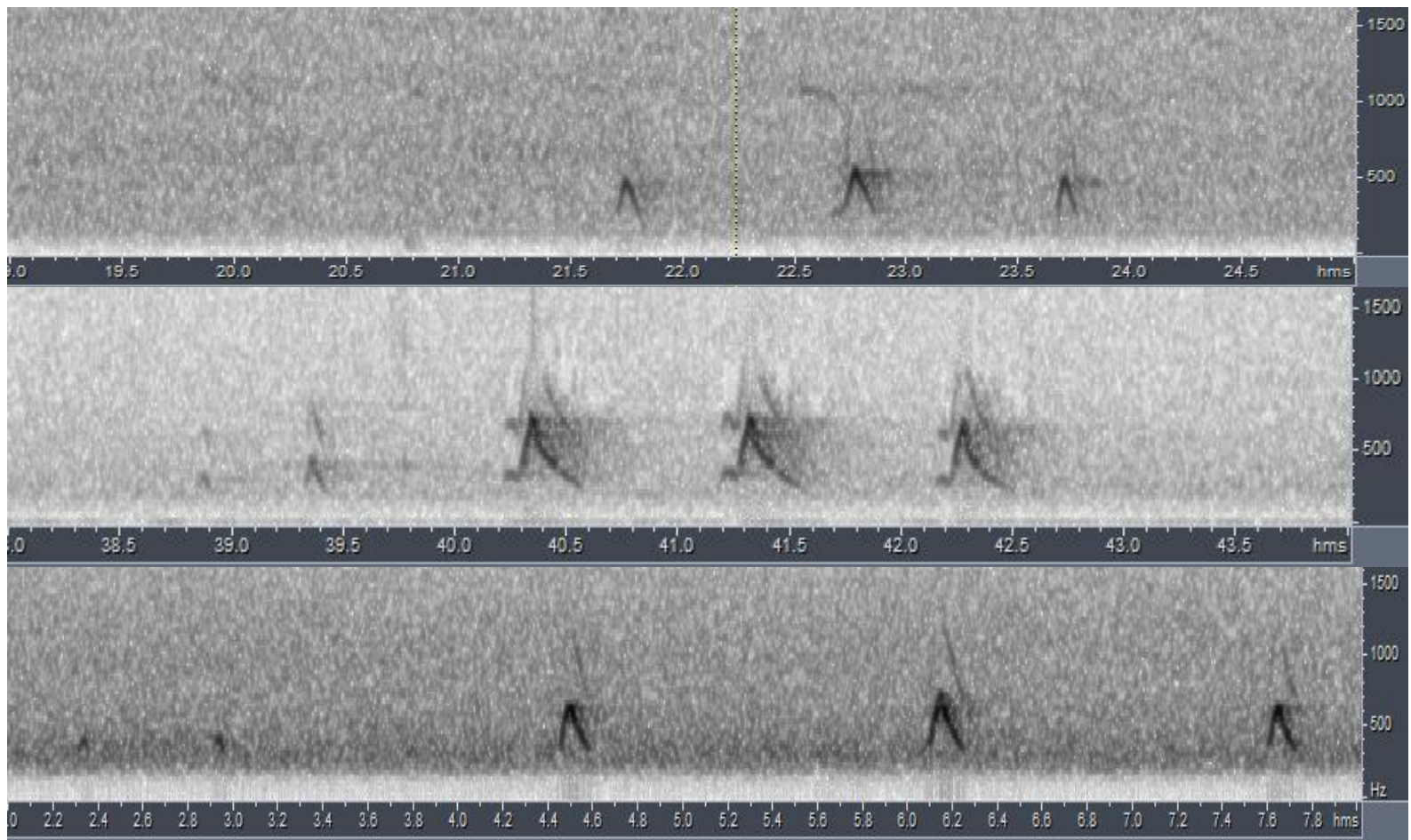

From top to bottom: XC230092: Chiapas, Mexico, Peter Boesman; XC76718: Guatemala, Doug Knapp;

XC274426: Costa Rica, Peter Boesman.

\section{virgata}

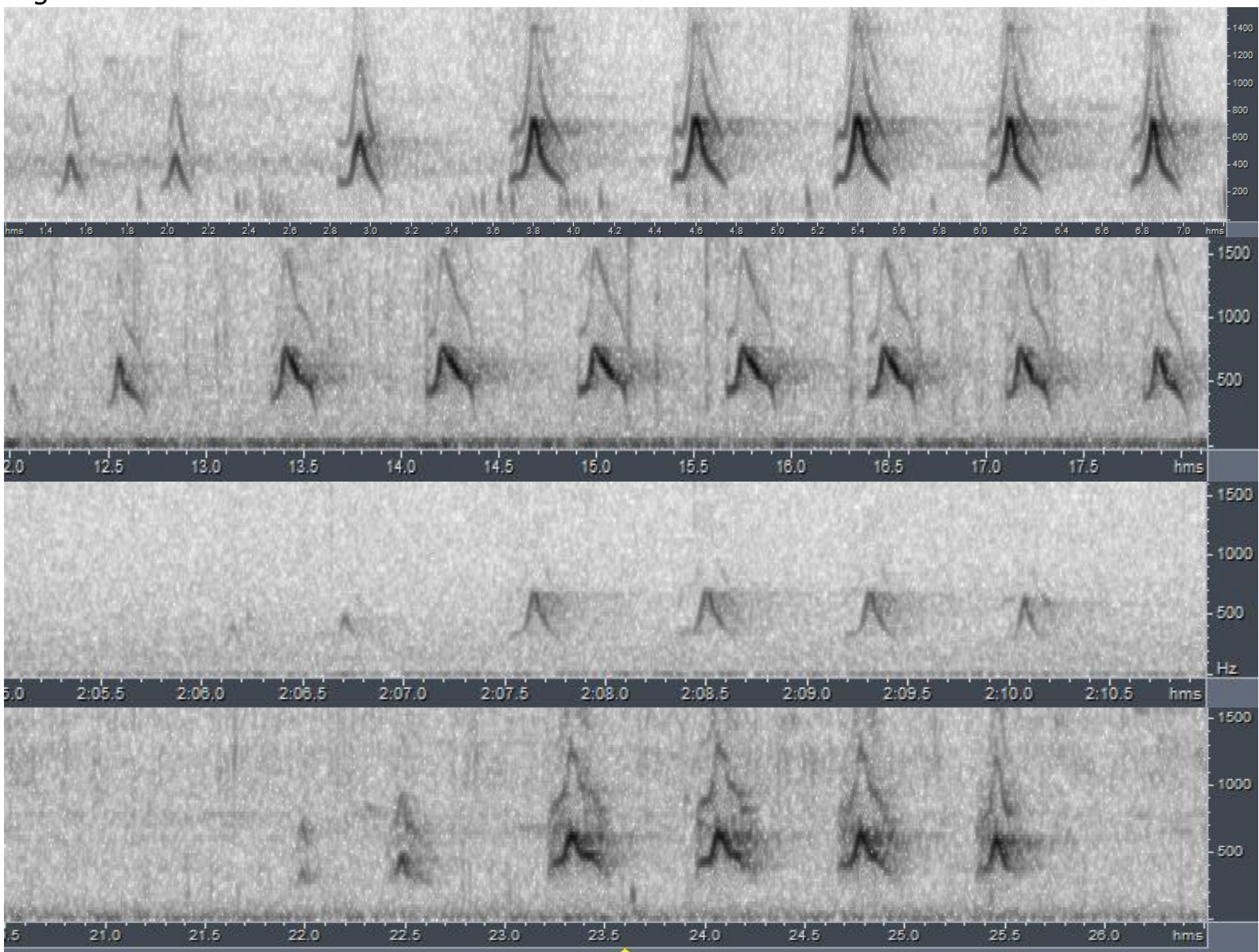




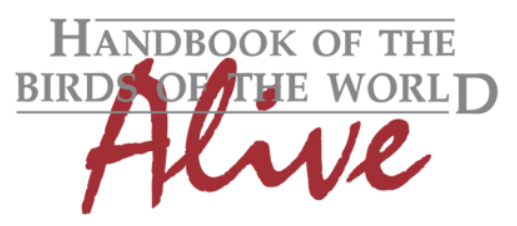

\section{ORNITHOLOGICAL NOTES}

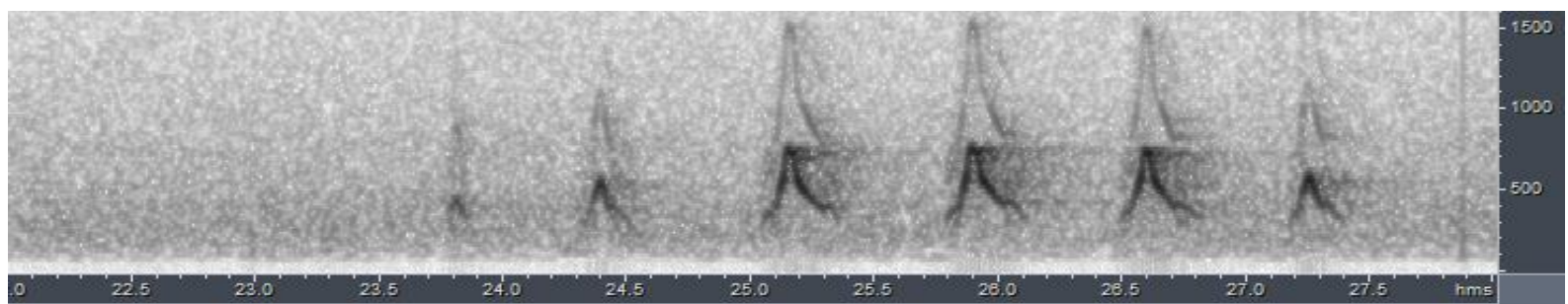

From top to bottom: XC97077: Tumbes, Peru, Dan Lane; XC261651: Esmeraldas, Ecuador, Olaf Jahn; XC244982: Magdalena Valley, Colombia, Oscar Marín; XC230095: Carabobo, Venezuela, Peter Boesman; XC11528: Monagas, Venezuela, Doug Knapp.

Group 2. Song is a series of 5-9 rather subdued hoots (with some variation, see below). This voice can be heard in the Guianas, the Amazon Basin and the Atlantic Forest.

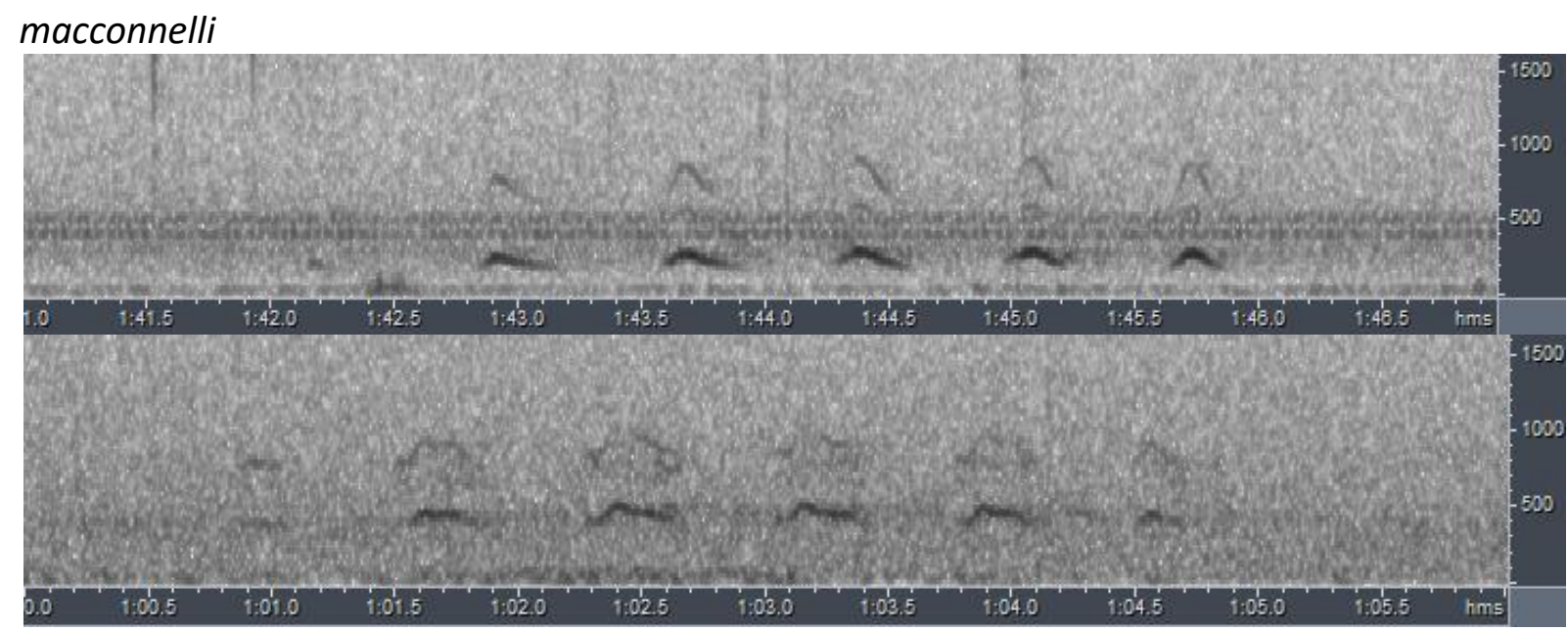

From top to bottom: ML14505: Guyana, Mark Robbins; ML11602: Suriname, Thomas Davis.

\section{superciliaris}

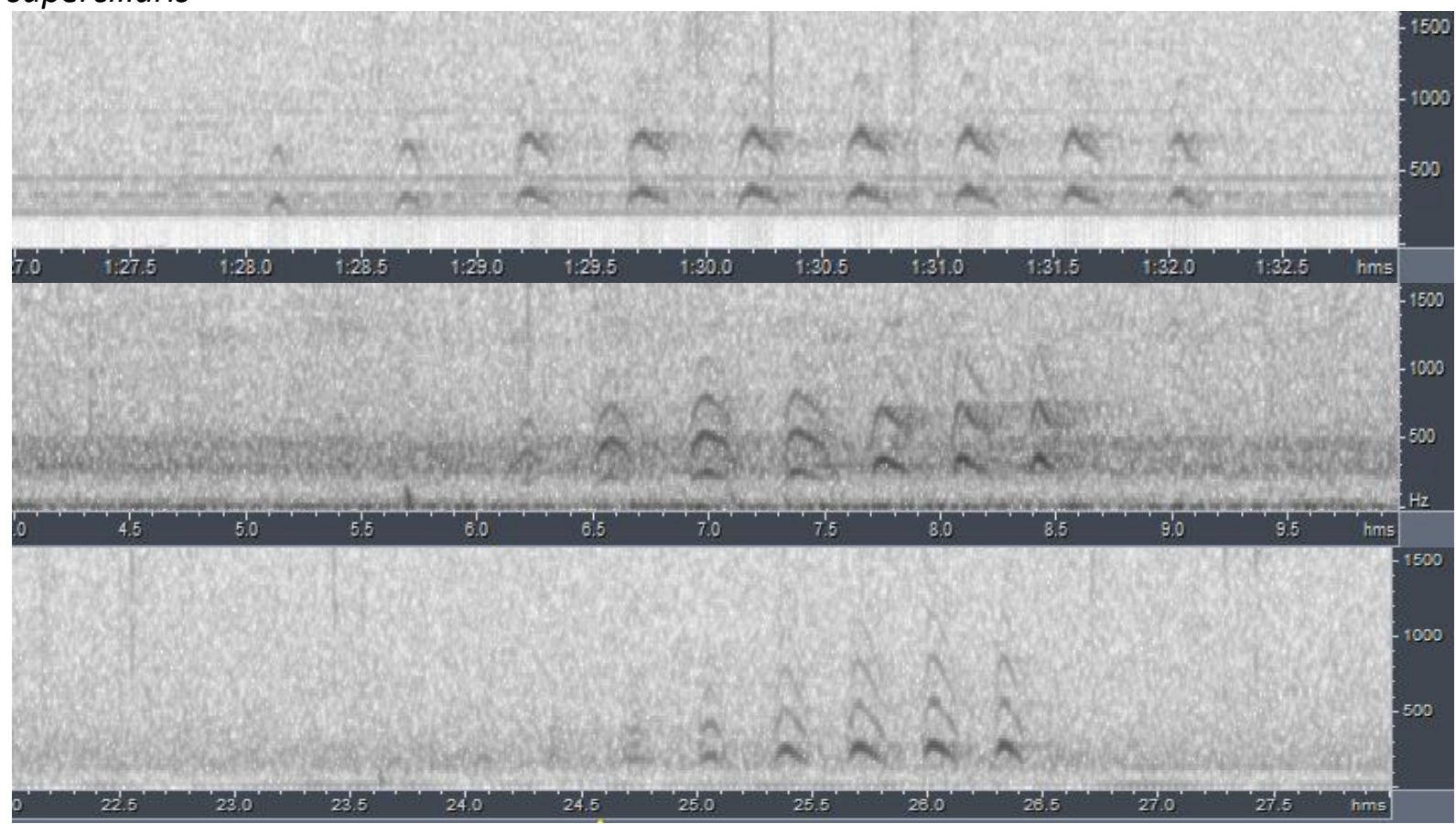

From top to bottom: XC97086: Loreto, Peru, Dan Lane; XC118836: Rondônia, Brazil, Gabriel Leite; XC304876 Pará, Brazil, Sidnei Dantas. 


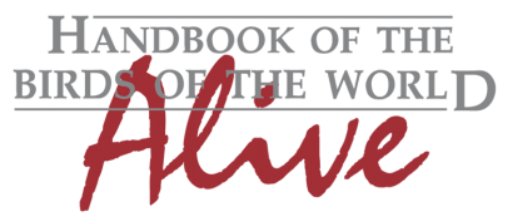

\section{ORNITHOLOGICAL NOTES}

\section{borelliana}

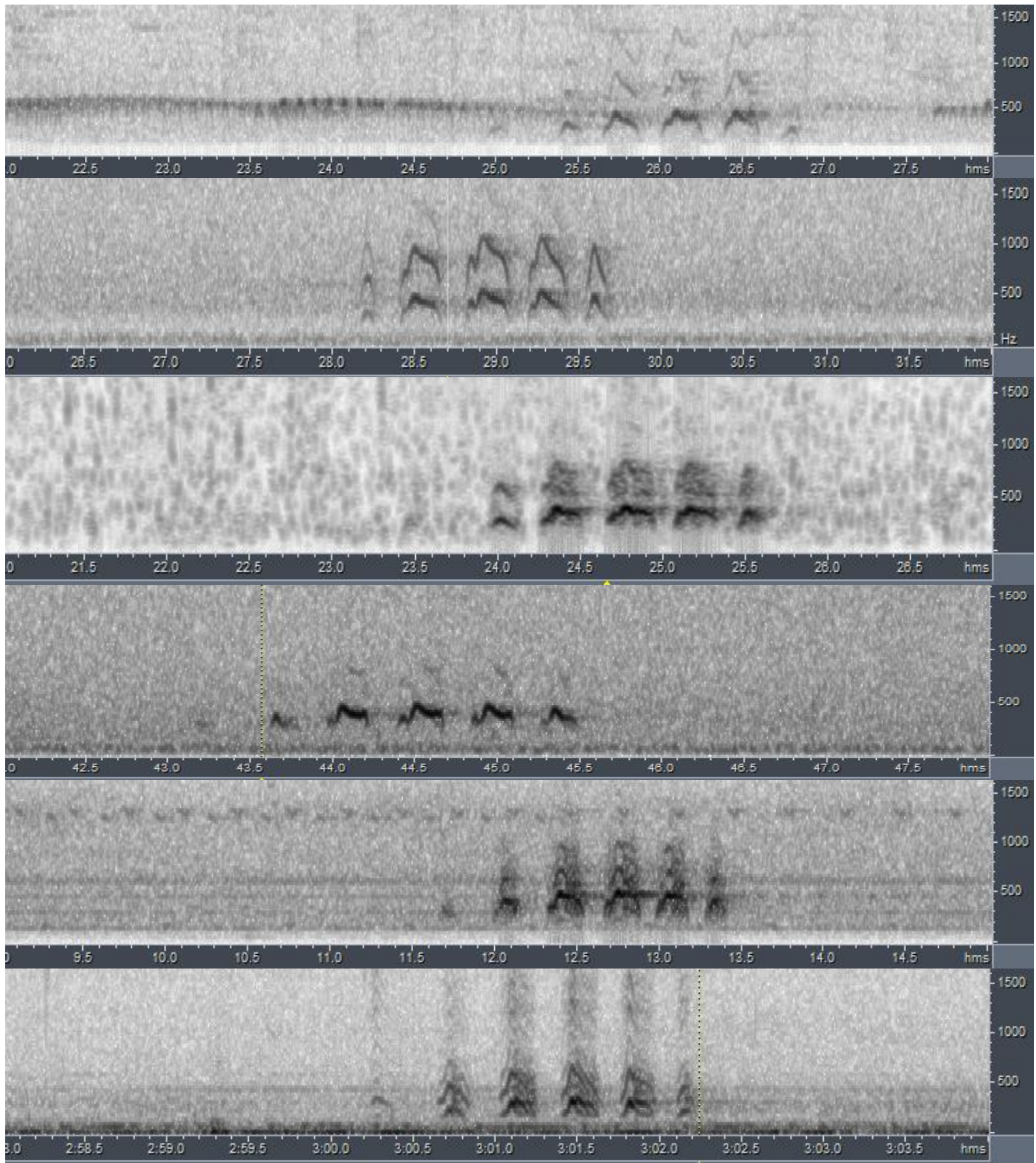

From top to bottom: XC210365: São Paulo, Brazil, Rodrigo de la Rosa; XC320324: Santa Catarina, Brazil, Alexandre Bianco; XC315460: Santa Catarina, Brazil, Eduardo Patrial; ML135648: Misiones, Argentina, Juan Areta; XC55665: Itapúa, Paraguay, Myriam Velázquez; ML166782: Chaco, Argentina, Juan Areta.

The above examples show clear vocal differences in the song:

Group 1 has a song comprising sharply overslurred notes, clearly visible as an upside down Vshape in the sonograms. Base frequency of the central notes reaches frequencies well above $500 \mathrm{~Hz}$ (maximum frequency: average $776 \mathrm{~Hz}, \mathrm{SD} 110 \mathrm{~Hz}, n=20$ ). Hoots are given at a leisurely pace, typically with pauses of 0.5 seconds or more. Pitch and pace may vary somewhat, depending on the level of excitement. 

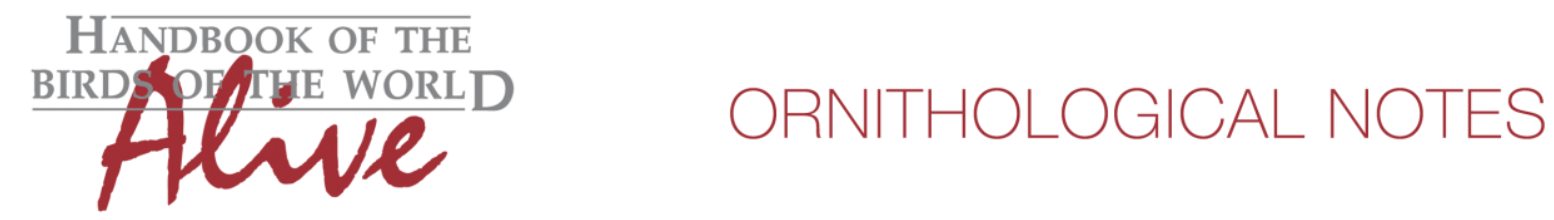

Group 2 has a song of much less emphasized hoots, and maximum base frequency typically remains around $500 \mathrm{~Hz}$ (maximum frequency: average $485 \mathrm{~Hz}, \mathrm{SD} 82 \mathrm{~Hz}, n=12$ ). Within this group, each race appears to display further subtle differences: Guianan macconnelli seems to have a distinctly slower song $(n=2)$, while hoots in Amazonian superciliaris are shorter and less modulated than in southern borelliana. In the latter two subspecies, the pace is notably faster than in Group 1.

Vocal differences can be quantified by applying the Tobias criteria. Both groups differ in maximum frequency (effect size 3.0, score 2) and in pace (score 2, except race macconnelli), which would give a total vocal score of 4 . Within group 2, each race can also be identified by voice with reasonable confidence (based on the few available recordings!). If this is further confirmed when more recordings become available, it is likely that quantification of vocal differences for these three taxa would also lead to a total score of about 3 in a pair-wise comparison.

Koenig et al. (2009) treated the Mottled Owl complex as two distinct species, Mexican WoodOwl (including races squamulatus, tamaulipensis and centralis) and Mottled Wood-Owl (comprising the other four races), citing their vocal distinctiveness as one of the main reasons for this treatment. From the above, it is clear that nominate virgata (at least vocally) also pertains to the northern group (the northern species would then be named $C$. virgata, although the type locality for this taxon 'Bogotá' as vaguely defined by Cassin (1849) and more precisely by von Berlepsch (1908) is very unlikely to be accurate, thus any detailed taxonomic revision will require some nomenclatural action).

Vocal distinctiveness of both groups was noted previously within Peru (Sanchez et al. 2012), but a comparative analysis over the entire range has not been performed until now.

Where the ranges of both groups meet, it is interesting to investigate the issue in further detail. Recordings from S Tachirá in W Venezuela (elevation 1100 m; e.g. ML59905) and E Ecuador (elevation 1350 m; e.g. XC99430) clearly pertain to Group 1, which suggests that taxon virgata also occurs along the $\mathrm{E}$ Andes $\mathrm{S}$ to Ecuador. In this region, it is parapatric with race superciliaris of the Amazon Basin. However, observations of this taxon are quite rare, especially in NW Amazonia, with apparently no voice recordings available from Amazonian Colombia and Venezuela (ML112266 is erroneously attributed to Mottled Owl, but is in fact a call of Spectacled Owl Pulsatrix perspicillata). Equally, the easternmost recordings pertaining to Group 1 are from Caño Colorado, Monagas, NE Venezuela, just N of the Orinoco (XC230106), while Group 2 reaches the S Orinoco Delta (ML145505).

Voice is an increasingly important element in assessing taxonomic status, and in particular in Strigidae, several recent cases have been largely influenced by vocal characters. It would seem that in the Mottled Owl complex, there is a clear vocal divergence between the abovementioned two groups, which meet both in the N Andean foothills (where they may be parapatric) and around the Orinoco Delta, which clearly forms a physical barrier. There is therefore a strong indication that two species may be involved. 

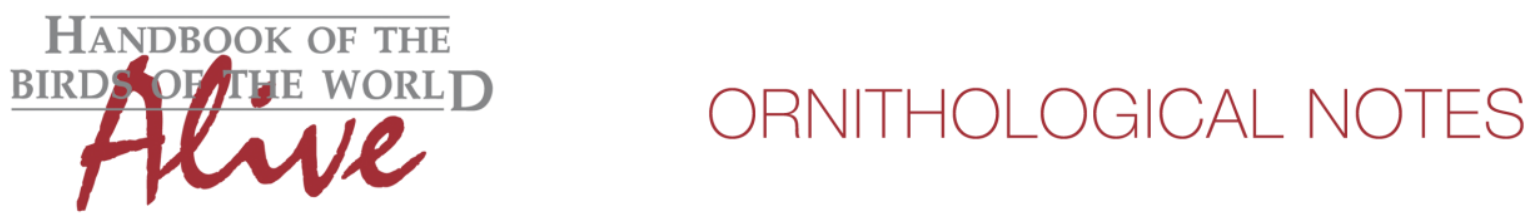

This note was finalized on 21st March 2017, using sound recordings available online at that time. I thank, in particular, the many sound recordists who made their recordings of this species available on XC and ML and Guy Kirwan for revising the original text.

\section{References}

Berlepsch, von H. (1908). On the Birds of Cayenne, Novit. Zool. Vol. 15 (2): 288.

Cassin, J. (1848). Descriptions of owls, presumed to be undescribed, specimens of which are in the collection of the Academy of Natural Sciences of Philadelphia. Proceedings of the Academy of Natural Sciences of Philadelphia, 4: 121-125.

Koenig C., Weick, F. \& Becking, J.-H. (2009) Owls of the World. 2nd edition. Christopher Helm, London.

Sánchez, C., Saucier, J.R., Benham, P., Lane, D.F., Gibbons, R.E., Valqui, T., Figueroa, S.A., Schmitt, C., Sánchez, C., Schmidt, B.K., Milensky, C.M., García Bravo, A. \& García Olaechea, D. (2012) New and noteworthy records from northwestern Peru, Department of Tumbes. Bol. UNOP 7(2): 18-36.

Tobias, J.A., Seddon, N., Spottiswoode, C.N., Pilgrim, J.D., Fishpool, L.D.C. \& Collar, N.J. (2010) Quantitative criteria for species delimitation. Ibis 152(4): 724-746.

\section{Recommended citation}

Boesman, P. (2016). Notes on the vocalizations of Mottled Owl (Ciccaba virgata). HBW Alive Ornithological Note 450. In: Handbook of the Birds of the World Alive. Lynx Edicions, Barcelona. (retrieved from http://www.hbw.com/node/931753 on 25 March 2017). 